\title{
Dental student forensic knowledge and skills
}

\begin{abstract}
Background: Dental forensics is an area of dental research and knowledge in which students receive limited exposure. The purpose of this research was to evaluate dental student knowledge about dental forensics and to evaluate dental student skills in comparing radiographs.
\end{abstract}

Methods: Dental students $(\mathrm{N}=152)$ were provided 10 radiographs of extracted teeth. One of the radiographed teeth was heat-altered to $600{ }^{\circ} \mathrm{C}$ for 15 minutes. The students were asked to match the heat-altered tooth's radiograph to one of the 10 radiographs. A 10 -question survey concerning dental forensics was also presented to the students.

Results: There were $92.1 \%$ of dental students who were able to correctly identify a heataltered tooth's radiograph from the 10 radiographs provided. Of the 10 questions provided, 5 had a correct response rate above $70 \%$.

Conclusion: Dental students were successful in matching a dental radiograph of a heataltered tooth and its original radiograph. However, there is a need for current and emerging information about dental forensics.
Volume 6 Issue $6-2018$

\author{
Mona Sivaneri,' Constance Wiener R, ${ }^{2}$ \\ Alcinda K Trickett Shockey, ${ }^{3}$ Christopher \\ Waters ${ }^{4}$ \\ 'School of Medicine, West Virginia University, USA \\ ${ }^{2}$ Department of Dental Practice and Rural Health, West Virginia \\ University, USA \\ ${ }^{3}$ Department of Periodontics, West Virginia University, USA
}

${ }^{4}$ Department of Dental Research,West Virginia University, USA

\begin{abstract}
Correspondence: Constance Wiener R, Department of Dental Practice and Rural Health, School of Dentistry, West

Virginia University, Morgantown, 104a Health Sciences Addition, PO Box 9415WV 26506, Tel 304 58I-1960,
\end{abstract}

Email rwiener2@hsc.wvu.edu

Received: January 31, 2017 | Published: December 31, 2018

Keywords: forensics, needs assessment, dental identification

\section{Introduction}

Teeth are the strongest tissues of the human body, therefore are the least susceptible to destruction, ${ }^{1}$ even when compared with bones, particularly when subject to heat. Drastic changes in bone properties during burning can cause great difficulties in forensic identification tests. These changes to burnt bone, such as heat-induced shrinkage and deformation alter the morphological indicators that are critical for identification. ${ }^{2}$ In addition to the ability to withstand a significant amount of heat, the anatomy of teeth is unique from individual to individual and, as such, is used in human identification. ${ }^{1}$ When a massive disaster happens within a population, there is one task that must be completed to assure closure for many survivors. That task is victim identification. In disasters with thousands of victims, the most common records used and available for identification are dental records, ${ }^{1}$ particularly dental radiographs. Other new and innovative techniques, such as DNA technology in forensic dentistry are also becoming very important in human identification; ${ }^{3}$ however, DNA is heat-labile, whereas, teeth, as well as restorations, are able to withstand heat unless the teeth are exposed to a direct flame. ${ }^{4}$ The foundation of identification through dental remains begins by comparing the teeth as well as the occlusion, with available dental records. ${ }^{4}$ Comparing ante mortem and postmortem dental radiographs are the most dependable methods of determining an individual's dental remains. ${ }^{4}$ Many other techniques are being developed in dental forensics to provide higher scientific certainty for the results of burnt bone/teeth identification. These developmental applications include the use of cone-beam computed tomography, ${ }^{5}$ the identification of restorative dental materials through microscopy and elemental analyses that may be useful even with cremation, ${ }^{6}$ and computer algorithms of ante mortem and postmortem dental records. ${ }^{7}$ In a recent reliability study, raters using a cone-beam computed tomography imaging technique were able to make accurate visual comparisons with ante mortem radiographs. ${ }^{8}$ In cases where ante mortem records are not currently available, a forensic dentist can create a postmortem dental profile to be saved for any potential future availability or disclosure of ante mortem records. ${ }^{9}$ With all of these advancing technologies in forensic identification, there is still a critical need for dental professionals to be able to make comparisons of radiographs in a patient's chart and radiographs of victims taken after a disaster. Dental students need to learn how to make comparisons. The purpose of this research was to evaluate dental student knowledge about dental forensics and to evaluate dental student skills in comparing radiographs. Our central hypothesis is that there is no difference in the ability of dental students at each level of their education in making comparisons of radiographs, and in their knowledge of dental forensics.

\section{Materials and methods}

Ten extracted maxillary first molars were selected, autoclaved, measured, photographed Figure 1 and digitally radio graphed. One of the first molars was placed into a dental burn-out oven and heat-altered to $600{ }^{\circ} \mathrm{C}$ for 15 minutes. The burnt tooth was then digitally radio graphed. These radiographs Figure 2 were presented with a scenario as part of a questionnaire that also included Likert-style questions relating to dental forensics. First year dental students through third year dental students from one university were asked to identify which of the 10 teeth was the burnt tooth via radiographs and to respond to the Likert-style questions. The eligibility criteria were that students were registered as dental students, and at least age 18 years.

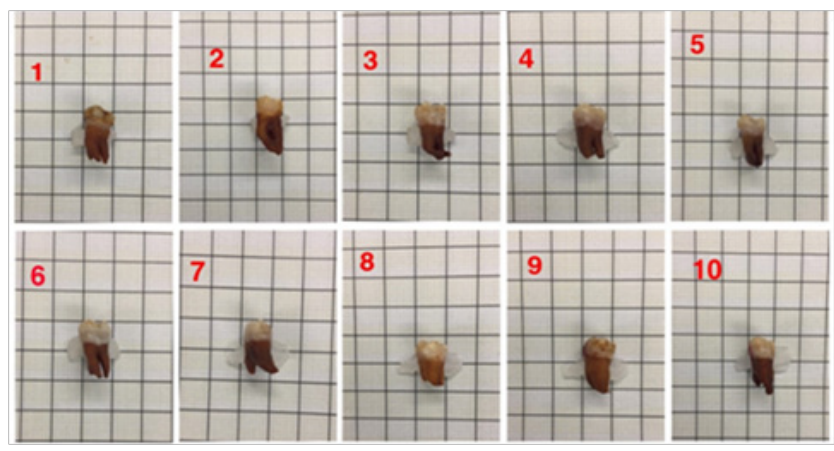

Figure I Photograph of I0 maxillary first molars used in the study. Note: Molars were stabilized by wax. 


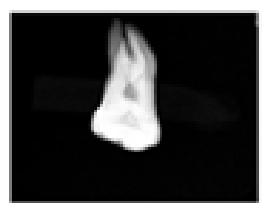

Heal-albered

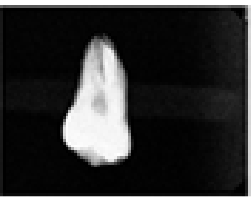

Radiograph 5.

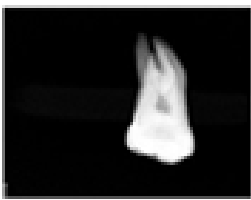

Radiograph 1. Makdter beat-altered tooth

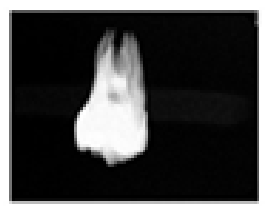

Radoyraph 6.

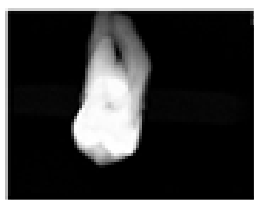

Radiograph 2

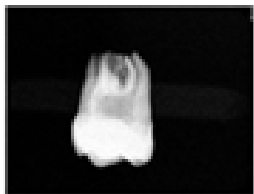

Ratiograph 7 .

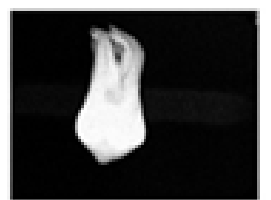

Radiograph 3

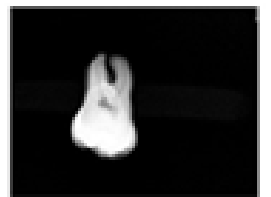

Radiograph a

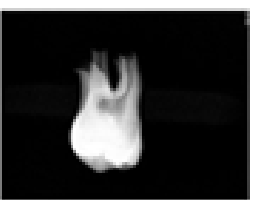

Radiograph 4

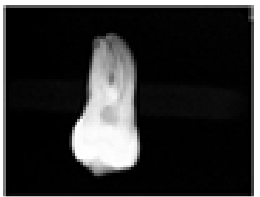

Radiograph 9

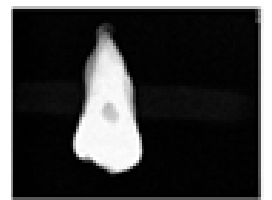

Rutiograph 10.

Figure 2 Radiographs presented to students.

\section{Results and discussion}

West Virginia University Institutional Review Board approved this study (Protocol number 1607188209). Of the 152 students who participated in the study, $52 \%$ were female. There were 50 first year students, 46 second year students and 56 third year students. Most $(79.6 \%)$ were non-Hispanic white Table 1 . When the students were asked to match the radiograph of the burnt tooth from the radiographs of the 10 teeth, including the match, $92.1 \%$ responded correctly. Responses to the Likert-style dental forensics needs assessment survey questions are presented in Table 2. Additionally, answers were collapsed into 2 categories: agree (which included strongly agrees and agree); and, disagree (which included neutral, disagree and strongly disagree).The percentages of correct dichotomized responses are also presented in Table 2. Not presented in tabular form are the results of class year and percentage of correct dichotomized responses as there were no significant differences among the classes in the responses. Similarly, not presented in tabular form are the results based on sex as there were no significant differences between male and female student responses. Of the 10 questions provided, $70 \%$ of the students responded accurately to 5 questions when the responses were dichotomized. There were 2 questions, in which $75 \%$ of the students responded accurately. These were "Forensic odontology means 'dealing with the time of death,' (false) and "Altering original dental images may result in inaccurate identifications should a disaster requiring dental forensics occur" (true). The researchers of this study evaluated professional dental students' educational knowledge base of dental forensics and its application. The vast majority (92.1\%) of the participants (at all levels of their education) were able to correctly match a radiograph of the altered tooth by extreme heat with that of the radiographs of the 10 original unaltered teeth. The ability to determine anatomic characteristics to make the match is a tribute to their knowledge of dental anatomy and radiology. Dental forensics is a field in which new knowledge, procedures, technology, and applications are being developed. It is important that such knowledge is clinically translated. Clinical translation involves the movement from unawareness to use of evidence. Therefore, although the ability to match radiographs is of paramount importance in identification, there is also a need to know about the advances and techniques in dental forensics, as well as, the need for accurate record-keeping habits and knowledge associated with the regulations concerning record-keeping. ${ }^{10}$ The results of the other survey questions indicate that there is a need to address the emerging knowledge associated with dental forensics.

Table I Characteristic of the Dental Student Participants

$$
\text { Frequency }(\mathbf{N}) \quad \%
$$

Sex

Male

Female

Race

Non-Hispanic White

Other

Class Rank

First year dental students

Second year dental students 


\begin{tabular}{|c|c|c|c|c|c|c|}
\hline & Disagree & $\begin{array}{l}\text { Strongly } \\
\text { disagree }\end{array}$ & $\begin{array}{l}\text { Correct } \\
\text { response }\end{array}$ & $\begin{array}{l}\text { Strongly } \\
\text { agree }\end{array}$ & Agree & Neutral \\
\hline Did the student match the correct original radiograph? & (140) $92.1 \%$ & & & & & \\
\hline $\begin{array}{l}\text { If a single rooted tooth had an endodontic procedure, is it possible } \\
\text { to match ante and post-mortem radiographs. }\end{array}$ & (True) $74.3 \%$ & (2I) $13.8 \%$ & (92) $60.5 \%$ & (23) $15.1 \%$ & (I2) $7.9 \%$ & (2) $1.3 \%$ \\
\hline $\begin{array}{l}\text { The shape of palatal rugae remain consistent and are reliable forensic } \\
\text { markers. }\end{array}$ & (True) $25.7 \%$ & (9) $5.9 \%$ & (30) $19.7 \%$ & (34) $22.4 \%$ & (65) $42.8 \%$ & (I3) $8.6 \%$ \\
\hline Forensic odontology means "dealing with the time of death." & (False) $85.5 \%$ & (5) $3.3 \%$ & (16) $10.5 \%$ & (23) $15.1 \%$ & (67) $44.1 \%$ & (39) $25.7 \%$ \\
\hline $\begin{array}{l}\text { 2D bar codes are most commonly used in dentures of people with } \\
\text { Parkinson's and neurodegenerative diseases. }\end{array}$ & (True) $44.7 \%$ & (II) $7.2 \%$ & (57) $37.5 \%$ & (65) $42.8 \%$ & (14) $9.2 \%$ & (4) $2.6 \%$ \\
\hline $\begin{array}{l}\text { Mesiodistal width of incisors can discriminate between male and } \\
\text { females and are routinely used in court as evidence of sex. }\end{array}$ & (False) $70.4 \%$ & (9) $5.9 \%$ & (36) $23.7 \%$ & (29) $19.1 \%$ & (60) $39.5 \%$ & (I8) II.8\% \\
\hline $\begin{array}{l}\text { Altering original dental images may result in inaccurate identifications } \\
\text { should a disaster requiring dental forensics occur. }\end{array}$ & (True) $86.8 \%$ & (70) $46.1 \%$ & (62) $40.8 \%$ & (I4) $9.2 \%$ & (4) $2.6 \%$ & (2) $1.3 \%$ \\
\hline $\begin{array}{l}\text { 14Carbon dating of teeth can be used to determine a person's age } \\
\text { within an error of } \pm 1.75 \text { years. }\end{array}$ & (True) $62.5 \%$ & (I4) $9.2 \%$ & (8I) $53.3 \%$ & (48) $31.6 \%$ & (7) $4.6 \%$ & (2) $1.3 \%$ \\
\hline $\begin{array}{l}\text { The lightest striae of Retzius (the neonatal line) is associated with a } \\
\text { stress of teething. }\end{array}$ & (False) 65.8\% & (II) $7.2 \%$ & (40) $26.3 \%$ & (48) $31.6 \%$ & (44) $28.9 \%$ & (8) $5.3 \%$ \\
\hline $\begin{array}{l}\text { In adult radiographs, physiologic changes can be seen as widening of } \\
\text { pulp area. }\end{array}$ & (False) 63.8\% & (I8) $11.8 \%$ & (36) $23.7 \%$ & (I7) $11.2 \%$ & (43) $28.3 \%$ & (37) $24.3 \%$ \\
\hline Use of third molar development as a legal landmark of age is valid. & (False) $70.4 \%$ & (8) $5.3 \%$ & (33) $21.7 \%$ & (32) $21.1 \%$ & (48) $31.6 \%$ & (27) $17.8 \%$ \\
\hline
\end{tabular}

\section{Comparative studies}

This study is innovative, and as such there are few other studies in the literature with which to compare the needs assessment of dental students in regard to dental forensics. A somewhat similar study involved 10 dental students in Denmark. Researchers learned that the students were able to match human skulls with radiographs, however, half of the students in that study made false positive matches. ${ }^{11}$ In a survey of 273 dental hygiene students, $93 \%$ indicated that they had not received formal education in disaster preparedness, but viewed themselves as professionals who could provide many tasks in disaster response. ${ }^{12}$ This current study could therefore be strengthened with determining the dental forensics knowledge and skills of dental hygiene students in addition to having evaluated dental students.

\section{Future research}

There is a need for future research in the dental and dental hygiene programs involving forensics. Researchers reported that $58 \%$ of respondents from the nation's dental schools with forensics programs had primarily didactic courses. ${ }^{13}$ Several dental schools with forensics curricula in place ${ }^{14,15}$ included elective or required courses with handson exercises. Future research is also needed concerning the possible inclusion of dental forensics on a national level as a measurable competency by the American Dental Association/American Dental Hygiene Association/Commission on Accreditation.

\section{Strengths and weaknesses}

This study is important in understanding the need for dental education relating to dental forensics. One of its strengths is the number of students who participated. This provided an adequate sample size for the study. In addition, each of the survey questions had at least a $97 \%$ completion. A weakness of the study is that only one school, with a student population predominately non-Hispanic white, was used for the study. Therefore racial/ethnic differences were not included in the study. Also, as the age of the students was predominately 22-26 years, age was not included in the study.

\section{Conclusion}

Dental forensics is an important consideration. With the size of healthcare workforce only second in size to the U.S. military, healthcare professionals are important as potential responders to terrorism and other public health emergencies, including the identification of victims. ${ }^{16}$ Preparation is essential. In this study, dental students were successful in matching a dental radiograph of a heataltered tooth and its original radiograph. However, there is a need for current and emerging information about dental forensics.

\section{Acknowledgments}

Drs. Wiener and Shockey received research support by the National Institute of General Medical Sciences of the National Institutes of Health under Award Number U54GM104942. The content is solely the responsibility of the authors and does not necessarily represent the official views of either the National Institutes of Health or the Department of State.

\section{Conflicts of interest}

The author declares that there are no conflicts of interest.

\section{References}

1. Auerkari E. Recent trends in dental forensics. IJLFS. 2008;1(1):5-12.

2. Imaizumi K. Forensic investigation of burnt human remains. Research and Reports in Forensic Medical Science. 2015;2015(5):67-74.

3. Silva RH, Sales-Peres A, Oliveira RN, et al. Use of DNA technology in forensic dentistry. JAOS. 2007;15(3):156-161.

4. Avon SL. Forensic odontology: the roles and responsibilities of the dentist. JCDA. 2004;70(7):453-458. 
5. Trochesset DA, Serchuk RB, Colosi DC. Generation of Intra-oral-like Images from Cone Beam Computed Tomography Volumes for Dental Forensic Image Comparison. J Forensic Sci. 2014;59(2):510-513.

6. Soon AS, Bush MA, Bush PJ. Complex layered dental restorations: Are they recognizable and do they survive extreme conditions? Forensic Sci Int. 2015;254:1-4.

7. Adams BJ, Aschheim KW. Computerized dental comparison: a critical review of dental coding and ranking algorithms used in victim identification. J Forensic Sci. 2016;61(1):76-86.

8. Ruder TD, Thali YA, Rashid SN, et al. Validation of post mortem dental CT for disaster victim identification. JOFRI. 2016;16(5):25-30.

9. Pretty IA, Sweet D. Forensic dentistry: A look at forensic dentistry-Part 1: The role of teeth in the determination of human identity. Br Dent $J$. 2001;190(7):359-366.

10. Basit A, Shah SM, Jameel RA, et al. Evaluation Of Dental Record Keeping At Hamdard Univeristy Dental Hospital. PODJ. 2016;36(1):38-41.
11. Wenzel A, Richards A, Heidmann J. Matching simulated antemortem and post-mortem dental radiographs from human skulls by dental students and experts: testing skills for pattern recognition. J Forensic Odontostomatol. 2010;28(1):5-12.

12. Bradshaw BT, Bruhn AP, Newcomb TL, et al. Disaster Preparedness and Response: A Survey of US Dental Hygienists. JDH. 2016;90(5):313-322.

13. Herschaft EE, Rasmussen RH. The teaching of forensic dentistry: a status report. J Dent Educ. 1978;42(9):532-536.

14. Stoeckel DC, Merkley PJ, McGivney J. Forensic dental training in the dental school curriculum. J Forensic Sci. 2007;52(3):684-686.

15. Hermsen KP, Johnson JD. A Model for Forensic Dental Education in the Predoctoral Dental School Curriculum.J DentEduc. 2012;76(5):553-561.

16. Markenson D, DiMaggio C, Redlener I. Preparing health professions students for terrorism, disaster, and public health emergencies: core competencies. Acad Med. 2005;80(6):517-526. 